\title{
A comparative study of efficacy of letrozole and clomiphene citrate for ovulation induction
}

\author{
Shaveta Jain ${ }^{1}$, Pushpa Dahiya ${ }^{1}$, Jyoti Yadav ${ }^{1}$, Nitin Jain ${ }^{2 *}$
}

\begin{abstract}
${ }^{1}$ Department of Obstetrics and Gynecology, Pt. B. D. Sharma, PGIMS, University of Health Sciences, Rohtak, Haryana, India

${ }^{2}$ Department of Radiology, Advanta Super Specialty Hospital and Trauma Centre, Rohtak, Haryana, India
\end{abstract}

Received: 03 August 2018

Accepted: 29 August 2018

*Correspondence:

Dr. Nitin Jain,

E-mail: logindrnitin@gmail.com

Copyright: (c) the author(s), publisher and licensee Medip Academy. This is an open-access article distributed under the terms of the Creative Commons Attribution Non-Commercial License, which permits unrestricted non-commercial use, distribution, and reproduction in any medium, provided the original work is properly cited.

\begin{abstract}
Background: This study was conducted to evaluate the efficacy of letrozole as an ovulation inducing agent and to compare it with clomiphene citrate (CC) in infertile women.

Methods: This study includes 100 women referred to gynecology OPD of Pt. B.D Sharma, PGIMS, Rohtak with infertility due to dysovulation. The patients were divided in two groups each comprised of 50 patients, Alternate women were enrolled in study group (Letrozole). Ultrasonic follicular monitoring was done on day 10, 12, 14, 16 of menstrual cycle to measure the number, size of mature follicles. Endometrial thickness and trilaminar pattern of endometrium was compared in between the groups. Inj. Gonadotrophin (hCG) was given as a trigger intramuscularly when follicle size was between 18 to $21 \mathrm{~mm}$. After 36 hours of hCG administration ovulation was confirmed on ultrasound.

Results: Mean age, parity, and the duration of infertility were similar in both groups. Ovulation rate was $81.6 \%$ in letrozole group and was higher than control group $(\mathrm{p}<.01)$. The average number of follicles in the control group was $1.90 \pm 0.77$ and $1.17 \pm 0.47$ in the study group $(\mathrm{p}<.001)$. Endometrial thickness in the study group was $7.55 \pm 1.12 \mathrm{~mm}$ and in the control group it was $6.06 \pm 0.87(\mathrm{p}<.01)$. Pregnancy rate in study group was $48 \%$ and control group $16 \%(\mathrm{p}<.05)$. Conclusions: Aromatase inhibitors (Letrozole) is a new group of drugs to join the arsenal of infertility treatments. The result of this preliminary study suggests that letrozole is associated with higher ovulation rate, higher endometrial thickness and trilaminar pattern thus resulting in higher pregnancy rate. Clomiphene citrate may be replaced by letrozole as primary treatment for ovulation induction in infertile patients.
\end{abstract}

Keywords: Aromatase inhibitor, Clomiphene, Infertility, Letrozole, Ovulation

\section{INTRODUCTION}

Infertility is defined as one year of unprotected intercourse without pregnancy. Primary infertility denotes those patients who have never conceived while secondary infertility is when a woman gives history of pervious conception. ${ }^{1}$ Infertility affects approximately $10-15 \%$ of couple in the reproductive age group which makes it an important component of the practice of the gynaecologist. ${ }^{2}$ In normal fertile couples, there is a $25 \%$ probability of becoming pregnant in each cycle. The cumulative pregnancy rate after 12 months is $85 \%$. After 12 months of unsuccessful pregnancy attempts, a cause should be explored because the likelihood of being normally fertile is only $15 \% .^{3}$ The probability for achieving a live birth without treatment decreases with increasing age and duration of infertility. Overall, the likelihood of success without treatment declines by about 
$5 \%$ for each additional year of female partner's age and by $15-25 \%$ for each added year of infertility. ${ }^{2}$

Therefore, every effort should be recommended to minimize the time needed to achieve a correct diagnosis of the infertility and to provide accurate information to the couple. ${ }^{4}$ Failure to ovulate is the major problem in approximately $40 \%$ of women with infertility, another $30-50 \%$ have tubal pathology and $10 \%$ or less have a cervical barrier. ${ }^{4}$

Various drugs are used for induction of ovulation e.g. human menopausal gonadotropin (HMG), follicle stimulating hormone (FSH), gonadotropin releasing hormone (GnRH) agonists, clomiphene citrate (CC), has been the first line of treatment for ovulatory disorders.

Gonadotropins are more effective than $\mathrm{CC}$ but are expensive and associated with higher risk of ovarian hyperstimulation syndrome and multiple gestations. In view of the disappointing results of $\mathrm{CC}$ treatment and the cost possible complications of gonadotropins, fertility care providers have been looking for a new easy to use, less expensive and more effective drug. ${ }^{5}$

Aromatase inhibitors have originally been developed for the treatment of breast cancer. Aromatase is a cytochrome P-450 haemoprotein and catalyzes the rate limiting step in the production of estrogen. Letrozole, a trizole derivative, is a highly potent, selective competitive and reversible aromatase inhibitor. It can be orally administered, easy to use and relatively inexpensive, with minor side effects. ${ }^{6}$ Compared with $\mathrm{CC}$, its use is associated with thicker endometrium, good ovulation rate and considerable number of pregnancies. ${ }^{6}$ Ovulation disorders are generally among the most easily diagnosed and most treatable causes of infertility. ${ }^{1}$ In the past, a woman with an ovulatory dysfunction had little hope of achieving a pregnancy. Today, if lack of ovulation is the only cause of infertility, a couple can expect their chances of conceiving to match the rate in general population with letrozole.

Therefore, present study was planned to compare the most commonly used drug i.e. clomiphene citrate for ovulation induction with letrozole a specific, reversible aromatase inhibitor.

\section{METHODS}

The present study was carried on hundred patients of primary/secondary infertility, attending OPD of Department of Obstetrics and Gynaecology, Pt. B. D. Sharma PGIMS, Rohtak. The patients were divided into two groups each comprised of 50 patients.

- Study Group: Letrozole $2.5 \mathrm{mg} /$ day from D3-D7 of menstrual cycle.

- Control Group: Clomiphene 50mg/day from D3-D7 of menstrual cycle.

\section{Inclusion criteria}

All infertile women with age 20-40 years, patent fallopian tubes, Women with dysovulation, normal semenogram, no evidence of genital tuberculosis, Alternate women were enrolled in study group (Letrozole).

\section{Exclusion criteria}

Male infertility, liver and kidney disease, hypo/ hyperthyroidism, diabetes etc. Women having any gynecological diseases.

Method: A detailed history was taken about menstrual cycle, any other symptoms referred to genital tract, duration of marriage, duration of cohabitation, any pervious history of surgical intervention, family history and personal history of tuberculosis, any excessive discharge, pain lower abdomen, history of PID, STD any history of orchitis in men, coital history (How frequently, what time and dyspareunia).

General physical examination, per abdomen and pelvic examination was done. All basic investigations listed in proforma were done. Ovulation inducing drugs were given to both the study group letrozole $2.5 \mathrm{mg}$ daily from day 3-7 menstrual cycle and control group clomiphene citrate $50 \mathrm{~g}$ daily from day 3-7 of menstrual cycle was given. Ultrasonic follicular monitoring was done on day $10,12,14,16$ of menstrual cycle to measure the number, size of mature follicles, endometrial thickness and trilaminar pattern of endometrium. Endometrial thickness was measured as a maximal thickness of endometrial lining in the plane through the central gonadotrophin (HCG) 10,000 IU intramuscularly, when follicle size is between 18 to $21 \mathrm{~mm}$. After 36 hours of $\mathrm{HCG}$ administration again ovulation was confirmed on ultrasound. She was called for examination whenever she misses her normal periods. Urine test for pregnancy was done on day 35.

In both groups, if there was ovulation but no pregnancy same dose of drug was repeated. In case of failure of ovulation, dose of same drug was doubled for the next cycles.

At the end of the study, the data were collected and analyzed statistically by using Student's t-test and chi square analysis.

\section{RESULTS}

In study group mean age was $27.34 \pm 4.38$ years and in control group mean age was $27.16 \pm 4.14$ years. Difference was not statistically significant $(\mathrm{p}>0.05)$. Mean BMI was $22.90 \pm 2.00 \mathrm{~kg} / \mathrm{m} 2$ in study group and $23.06 \pm 2.04 \mathrm{~kg} / \mathrm{m} 2$ in control group. Difference was statistically not significant $(\mathrm{p}>0.05)$. 
Table 1: Baseline demographic and clinical characteristics of patients of each group.

\begin{tabular}{|c|c|c|c|c|}
\hline & Letrozole & & Clomiphen & \\
\hline $\begin{array}{l}\text { Age (in } \\
\text { years) }\end{array}$ & Frequency & $\%$ & Frequency & $\%$ \\
\hline $20-25$ & 16 & 32 & 20 & 40 \\
\hline $26-30$ & 22 & 44 & 20 & 40 \\
\hline $31-35$ & 10 & 20 & 8 & 16 \\
\hline $35-40$ & 2 & 4 & 2 & 4 \\
\hline Total & 50 & 100 & 50 & 100 \\
\hline $\begin{array}{l}\text { Education } \\
\text { status }\end{array}$ & Frequency & $\%$ & Frequency & $\%$ \\
\hline Illiterate & 14 & 28 & 10 & 20 \\
\hline $\begin{array}{l}\text { Up to } \\
\text { Matric }\end{array}$ & 22 & 44 & 26 & 52 \\
\hline $\begin{array}{l}\text { Up to } 12^{\text {th }} \\
\text { class }\end{array}$ & 8 & 16 & 8 & 16 \\
\hline Graduate & 6 & 12 & 6 & 12 \\
\hline Total & 50 & 100 & 50 & 100 \\
\hline Occupation & $\begin{array}{l}\text { Husband } \\
(\%)\end{array}$ & $\begin{array}{l}\text { Wife } \\
(\%)\end{array}$ & $\begin{array}{l}\text { Husband } \\
(\%)\end{array}$ & $\begin{array}{l}\text { Wife } \\
(\%)\end{array}$ \\
\hline Labourer & 12 & 0 & 8 & 0 \\
\hline Housewife & - & 84 & - & 88 \\
\hline Teacher & 12 & 8 & 16 & 8 \\
\hline Business & - & 0 & 8 & 0 \\
\hline Farmer & 36 & 0 & 24 & 0 \\
\hline Driver & 12 & 0 & 8 & 0 \\
\hline Others & 28 & 8 & 36 & 4 \\
\hline Residence & Frequency & $\%$ & Frequency & $\%$ \\
\hline Rural & 32 & 64 & 36 & 72 \\
\hline Urban & 18 & 36 & 14 & 28 \\
\hline Total & 50 & 100 & 50 & 100 \\
\hline BMI $\left(\mathrm{kg} / \mathrm{m}^{2}\right)$ & Frequency & $\%$ & Frequency & $\%$ \\
\hline $18-19.9$ & 2 & 4 & 4 & 8 \\
\hline $20-21.9$ & 14 & 28 & 8 & 16 \\
\hline $22-23.9$ & 16 & 32 & 18 & 36 \\
\hline $24-25.9$ & 12 & 24 & 14 & 28 \\
\hline $26-27.9$ & 6 & 12 & 6 & 12 \\
\hline$>28$ & 0 & 0 & 0 & 0 \\
\hline Total & 50 & 100 & 50 & 100 \\
\hline \multirow[t]{2}{*}{$\begin{array}{l}\text { Duration of } \\
\text { infertility } \\
\text { (in years) }\end{array}$} & \multicolumn{2}{|l|}{ Letrozole } & \multicolumn{2}{|l|}{ Clomiphene } \\
\hline & Frequency & $\%$ & Frequency & $\%$ \\
\hline $1-2$ & 8 & 16 & 6 & 12 \\
\hline $2-4$ & 16 & 32 & 14 & 28 \\
\hline $4-6$ & 12 & 24 & 10 & 20 \\
\hline $6-8$ & 8 & 16 & 10 & 20 \\
\hline $8-10$ & 4 & 8 & 2 & 4 \\
\hline $10-12$ & 2 & 4 & 4 & 8 \\
\hline$>12$ & 0 & 0 & 4 & 8 \\
\hline Total & 50 & 100 & 50 & 100 \\
\hline
\end{tabular}

The mean duration of infertility in present study was $4.58 \pm 2.68$ years for letrozole group as compared to $5.62 \pm 3.47$ years in clomiphene group. Duration of infertility in different categories among the two groups was not statistically significant $(\mathrm{p}>0.05)$ as seen in Table 1.

In present study, letrozole was given during 218 cycles of 50 patients, ovulation occurred in $178(81.65 \%)$ cycles which was suggested by rupture of dominant follicle. In the control group, clomiphene citrate was given in 232 cycles of 50 patients and ovulation occurred in 152 $(65.51 \%)$ cycles. Ovulation rate in letrozole group was more and statistically highly significant $(\mathrm{p}<0.01)$ as compared to clomiphene.

Table 2: Comparison of outcomes (ovulation rate, single follicle formation, day of beta-hCG administration, endometrial thickness and pattern) between letrozole and clomiphene citrate groups.

\begin{tabular}{|c|c|c|c|c|}
\hline & \multicolumn{2}{|l|}{ Letrozole } & \multicolumn{2}{|c|}{ Clomiphene } \\
\hline Ovulation & Frequency & $\%$ & Frequency & $\%$ \\
\hline Occurred & 178 & 81.65 & 152 & 65.51 \\
\hline Not occurred & 40 & 18.34 & 80 & 34.48 \\
\hline Total & 218 & 100 & 232 & 100 \\
\hline $\begin{array}{l}\text { No. of } \\
\text { follicles }\end{array}$ & Frequency & $\%$ & Frequency & $\%$ \\
\hline 1 & 178 & 85.57 & 64 & 29.62 \\
\hline 2 & 20 & 9.61 & 120 & 55.55 \\
\hline 3 & 10 & 4.80 & 20 & 9.25 \\
\hline 4 & 0 & 0 & 12 & 5.55 \\
\hline Total & 208 & 100 & 216 & 100 \\
\hline $\begin{array}{l}\text { Day of beta- } \\
\text { hCG } \\
\text { administration }\end{array}$ & Frequency & $\%$ & Frequency & $\%$ \\
\hline 10 & 24 & 13.48 & 6 & 3.94 \\
\hline 12 & 136 & 76.40 & 46 & 30.26 \\
\hline 14 & 16 & 8.98 & 92 & 60.52 \\
\hline 16 & 2 & 1.12 & 8 & 5.26 \\
\hline Total & 178 & 100 & 152 & 100 \\
\hline $\begin{array}{l}\text { Endometrial } \\
\text { thickness } \\
(\mathbf{m m})\end{array}$ & Frequency & $\%$ & Frequency & $\%$ \\
\hline 5 & 10 & 4.58 & 60 & 25.86 \\
\hline 6 & 30 & 13.76 & 116 & 50 \\
\hline 7 & 50 & 22.93 & 36 & 15.51 \\
\hline 8 & 94 & 43.11 & 20 & 8.62 \\
\hline 9 & 26 & 11.92 & 0 & 0 \\
\hline 10 & 8 & 3.66 & 0 & 0 \\
\hline Total & 218 & 100 & 232 & 100 \\
\hline $\begin{array}{l}\text { Endometrial } \\
\text { pattern }\end{array}$ & Frequency & $\%$ & Frequency & $\%$ \\
\hline Trilaminar & 178 & 81.65 & 132 & 56.89 \\
\hline Non trilaminar & 40 & 18.34 & 100 & 43.10 \\
\hline Total & 218 & 100 & 232 & 100 \\
\hline
\end{tabular}

Table 2 shows distribution according to number of follicles in all the cycles. In the study group (letrozole)out of 208 cycles, $178(85.57 \%)$ cycle had 1 number of follicles. Mean number of follicles in study group was $1.17 \pm 0.47$. In the control group out of 216 cycles, 120 $(55.55 \%)$ cycles had 2 number of follicles. Mean number of follicles in control group was $1.90 \pm 0.77$. Number of 
follicles is letrozole group as compared to clomiphene was less and statistically significant $(\mathrm{p}<0.001)$.

In study group(letrozole) endometrial thickness was 8 $\mathrm{mm}$ in $43.11 \%$ cycles, mean endometrial thickness was $7.55 \pm 1.12 \mathrm{~mm}$. In the control group in $50 \%$ cycles the endometrial thickness was $6 \mathrm{~mm}$. Mean endometrial thickness was $6.06 \pm 0$. $87 \mathrm{~mm}$. This difference in thickness of endometrium was highly significant $(\mathrm{p}<0.01)$.

In study group $81.65 \%$ cycles showed trilaminar pattern while $18.34 \%$ cycles had non trilaminar pattern of endometrium. In control group $56.8 \%$ cycles had trilaminar pattern while $43.1 \%$ cycles had non trilaminar pattern $(\mathrm{p}<0.001)$.

Table 3: Comparison of outcomes (pregnancy rate and cycle of conception) between letrozole and clomiphene citrate groups.

\begin{tabular}{|lllll|}
\hline & Conception & Letrozole & \multicolumn{3}{c|}{ Clomiphene } \\
\hline Not & Frequency & $\%$ & Frequency & $\%$ \\
conceived & 26 & 52 & 42 & 84 \\
\hline Conceived & 24 & 48 & 8 & 16 \\
\hline Total & 50 & 100 & 50 & 100 \\
\hline $\begin{array}{l}\text { Cycle of } \\
\text { conception }\end{array}$ & Letrozole & & Clomiphene \\
\hline & Frequency & $\%$ & Frequency & $\%$ \\
\hline Cycle I & 4 & 16.66 & 2 & 25 \\
\hline Cycle II & 8 & 33.33 & 2 & 25 \\
\hline Cycle III & 12 & 50 & 4 & 50 \\
\hline Cycle IV & 0 & 0 & 0 & 0 \\
\hline Cycle V & 0 & 0 & 0 & 0 \\
\hline Total & 24 & 100 & 8 & 100 \\
\hline
\end{tabular}

Table 3 shows $48 \%$ conceived in study group while in control group $16 \%$ conceived. An almost three-fold increase in pregnancy rate was observed in patients who received letrozole compared to those who received clomiphene citrate, this difference was statistically significant $(\mathrm{p}<0.05)$.

In study group, $50 \%$ of patients conceived in cycle III. In control group $25 \%$ patient conceived in cycle I and cycle II and $50 \%$ in cycle III. None of patient conceived in cycle IV and V.

\section{DISCUSSION}

Infertility has been nasty thorn in many marital relations since the time known. Even today especially in rural areas, women who cannot bear children are looked down which add on to the primary stress of couples with infertility, who are desperate to have kids. Recent advanced technologies and newer medications have offered a lot of hope to such couples.
Present study compares clomiphene citrate with aromatase inhibitor letrozole for ovulation induction in infertile patients.

Demographic profile should be comparable between letrozole and clomiphene group to reduce the bias. In the present study, demographic characteristics of participants i.e. age, mean infertility period and BMI were comparable similar to study done by Atay et al who reported mean age of $27.2 \pm 0.9$ years in letrozole group $(n=51)$ vs. $26.2 \pm 1.1$ years in CC group $(n=55){ }^{7}$

The present study showed better ovulation rates in group with letrozole as evidenced by $81.65 \%$ ovulation achieved in this group compared to $65.5 \%$ in clomiphene group which were comparable with studies conducted by Atay et al and Mitwally et al. ${ }^{7,8}$ In the present study the ovulation rate in letrozole group was more and statistically highly significant $(\mathrm{p}<0.01)$ as compared to clomiphene group.

Because aromatase inhibitors do not deplete estrogen receptors, as does CC, normal central feedback mechanisms remain intact. As the dominant follicle grows and estrogen levels rise, normal negative feedback occurs centrally, resulting in suppression of FSH and atresia of the smaller growing follicles. A single dominant follicle, and mono-ovulation, should occur in most cases. ${ }^{9}$ This is in direct contrast with $\mathrm{CC}$ which leads to in higher estrogen level thereby resulting in increased number of follicles. ${ }^{10}$

In the present study; authors also observed a greater

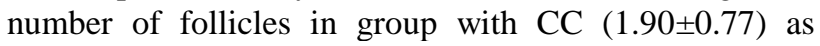
compared to group with letrozole $(1.17 \pm 0.47)$. Number of follicles in letrozole group as compared to clomiphene was less and statistically very highly significant $(\mathrm{p}<0.01)$ in the present study, this trend was reported by Fisher et al in their randomized, double blind study in which 19 normal healthy ovulatory volunteers not desiring pregnancy were randomized to receive either letrozole $2.5 \mathrm{mg}$ daily (9 patients) or CC $50 \mathrm{mg}$ daily (10 patients) on day 5-9. The results were compared with untreated cycles of the same patients. Single dominant follicle was found in the untreated cycles. 2.2 in the CC cycles and 1.7 in letrozole cycles. ${ }^{11}$

In another randomized trial of 49 patients with unexplained infertility by Sammour et al 24 patients were treated with $\mathrm{CC}$ and 25 with letrozole. On comparison they found, letrozole treatment was associated with a lower estrogen level, fewer follicle (1 versus 2 ) thicker endometrium and more stromal blood flow as compared to clomiphene citrate group. ${ }^{12}$ The present study results were also comparable to study done by Atay et al which demonstrate increased number of follicles in group with clomiphene citrate $(2.4 \pm 1.15)$ compared to letrozole group $(1.2 \pm 0.41){ }^{7}$ 
In the present study authors administered hCG (10000 IU IM) to trigger ovulation when at least one mature follicle $(\geq 18 \mathrm{~mm})$ developed. In present study the mean day of hCG administration in letrozole group was $11.78 \pm 1.57$ day while in clomiphene citrate group it was $13.34 \pm 1.28$ day. The day of hCG administration after the follicle has attained size $\geq 18 \mathrm{~mm}$ was earlier and statistically significant $(\mathrm{p}<0.05)$ in letrozole group in comparison to clomiphene group. These results are comparable to study done by Atay et al. ${ }^{7}$ Sammour et al concluded that patients in both groups required a similar period to satisfy the criteria for hCG administration (10 day in CC vs 11 days in LE group $\mathrm{p}=0.3)^{12} \mathrm{Al}$ Fozan et al found that duration to reach a dominant follicle was $10.1 \pm 0.3$ days in letrozole group and $10.8 \pm 0.9$ days in CC group. ${ }^{13}$

Endometrial thickness was as the maximal thickness of the endometrial lining in the plane through the central longitudinal axis of the uterine body. In the present study endometrial thickness was more in letrozole group $(7.55 \pm 1.12 \mathrm{~mm})$ than in CC group $(6.06 \pm 0.87 \mathrm{~mm})$ and this was very highly significant $(\mathrm{p}<0.001)$. The similar pattern is seen in most of other studies apart from $\mathrm{Al}$ Fozan et al, which demonstrates the reverse. ${ }^{13}$

The above results consolidate the belief that endometrium is one of the most important targets of the antiestrogenic effect of CC and may explain a large part of the lower pregnancy rate and possible higher miscarriage rate with CC. However, in general an endometrium that is less than 5 or $6 \mathrm{~mm}$ is usually associated with significant likelihood of failure to conceive. In addition, successful implantation requires a receptive endometrium, with synchronous development of glands and stroma. ${ }^{14} \mathrm{~A}$ reduction in endometrial thickness below the level thought to be needed to sustain implantation was found in up to $30 \%$ of women receiving CC according to Gonen et al. This could be due to prolonged estrogen receptor depletion in the endometrium. ${ }^{15}$

In the present study, trilaminar pattern of endometrium at the midcycle was seen in $81.65 \%$ of letrozole treated patient while only in $56.89 \%$ of CC group $(p<0.001)$. These results are comparable to fisher et al, who also demonstrated $71 \%$ of letrozole treated patients with trilaminar pattern of endometrium as compared to $44 \%$ of $\mathrm{CC}$ group. The investigators concluded that letrozole provides a better uterine environment. ${ }^{11}$

In the present study, pregnancy rate achieved after ovarian stimulation was $48 \%$ in letrozole and $16 \%$ in clomiphene. An almost three-fold increase in pregnancy rate was observed in patients who received aromatase inhibitor. The results were better than studies conducted by other authors like $21.6 \%$ in Letrozole versus $9.1 \%$ in clomiphene citrate by Atay $\mathrm{V}$ et al. ${ }^{7} 16.7 \%$ in letrozole vs. $5.6 \%$ in clomiphene by Sammour et al and $11.5 \%$ in Letrozole versus $8.9 \%$ in clomiphene citrate by Al Fozan et al and $26 \%$ in letrozole group by Begam et al. ${ }^{12,13,16}$
Present study showed such results because patients were of younger age and duration of infertility was also less.

\section{CONCLUSION}

For the last 40 years, the first line of treatment for anovulation in infertile women has been clomiphene. The choice of $\mathrm{CC}$ was appropriate because the drug was highly effective in inducing ovulation in selected patients with the advantages of being orally administered, relatively safe and inexpensive. In contrast, alternative treatments usually involved parenteral gonadotropins that were significantly more complicated and uncomfortable to administer, expensive and associated with more frequent and serious complications. However, CC was also found to have adverse effects, especially in the form of common antiestrogenic endometrial and cervical mucous changes that could prevent pregnancy in the face of successfully induced ovulation. Aromatase inhibitors are a new group of drugs to join the arsenal of fertility treatments. They are orally administered, easy to use and relatively inexpensive, with minor side effects. Based on the evidence reviewed above, these oral agent's aromatase inhibitor seems to be efficient for ovulation induction. Authors believe that a major advantage of letrozole for ovulation induction was mono-follicular ovulation. Compared with $\mathrm{CC}$, its use is associated with thicker endometrium, good ovulation rate and considerable number of pregnancies. The result of this preliminary study suggests that letrozole may replace $\mathrm{CC}$ as the first line treatment for women with ovulatory disorders.

\section{Funding: No funding sources Conflict of interest: None declared \\ Ethical approval: The study was approved by the Institutional Ethics Committee}

\section{REFERENCES}

1. Burney RO Sclurst DJ, Mayao MW. Infertility. In: Berek JS, eds. Berek and Novak's Gynecology. $14^{\text {th }}$ ed. New Delhi: Woltens Kluvenhealth; 2007:11851276.

2. Speroff L, Fritz MA, editors. Female infertility. In: Clinical gynaecologic endocrinology infertility. 7th ed. Philadelphia: Lippincott William and Wilkins; 2007: 1013-1068.

3. Carcio AH, ed. Causes of infertility. In: Management of infertile couple. Lippincott: Raven Publishers. 1999: 25-48.

4. Blumenfeld Z, Yoffe N, Bronshtein M. Transvaginal sonography in infertility and assisted reproduction a review. Obstet Gynaecol Survey .1990;36-49.

5. Holzer H, Casper R, Tulandi T. A new era in ovulation induction. Fertil Steril. 2006;85:277-84.

6. Bayar U, Tranriverdi HA, Barut A, Ayoglu F, Ozcan O, Kaya E. Letrozole vs clomiphene citrate in patients with ovulatory infertility. Fertil Steril. 2006;85:1045-8. 
7. Atay VC, Muhcu M, Cam M, Karateke A. Comparison of Letrozole and clomiphene cirate in women with polycystic ovaries undergoing ovarian stimulation. J Int Med Res. 2006;34:73-6.

8. Mitwally MFM, Casper RF. Use of an aromatase inhibitor for induction of ovulation in patients with an inadequate response to clomiphene citrate. Fertil Steril. 2001;75:305-9

9. Sioufi A, Gauducheau N, Pineau V, Marfil F, Jaouen A, Cardot JM, et al. Absolute bioavailability of letrozole in healthy postmenopausal women. Biopharmac Drug Disposition. 1997;18(9):779-89.

10. Kerin JF, Liu JH, Phillipou G, Yen SSS. Evidence for a hypothalamic site of action of clomiphene citrate in women. J Clin Endocrinol Metab. 1985;61:265-8.

11. Fisher SA, Rold RL, Vugt DA, Casper RF. A randomized double-blind comparison of effects of clomiphene citrate and the aromatase inhibitor letrozole on ovulatory function in normal women. Fertil Steril. 2002;78:280-5.

12. Sammour A, Biljan MM, Tan SL, Tulandi T. Prospective randomized trial comparing the effects of letrozole (LE) and clomiphene citrate (CC) on follicular development, endometrial thickness and pregnancy rate in patients undergoing superovulation prior to intrauterine insemination (IUI). Fertil Steril. 2001;76:110-7.

13. Al-Fozan H, Al-Khadouri M, Tan SL, Tulandi T. A randomized trial of letrozole versus clomiphene citrate in women undergoing superovulation. Fertil Steril. 2004;82:1561-3.

14. Hammond M, Halme J, Talbert L. Factors affecting the pregnancy rate in clomiphene citrate induction of ovulation. Obstet Gynaecol. 1983;62:196-202.

15. Gonen Y, Casper RF. Sonographic determination of an adverse effect of clomiphene citrate on endometrial growth. Hum Reprod. 1990;5:670-4.

16. Begum MR, Quadir E, Begum A, Begum RH, Begum M. Role of aromatase inhibitor in ovulation induction in patients with poor response to clomiphene citrate. J Obstet Gynaecol Res. 2006;32:502-6.

Cite this article as: Jain S, Dahiya P, Yadav J, Jain $\mathrm{N}$. A comparative study of efficacy of letrozole and clomiphene citrate for ovulation induction. Int $\mathrm{J}$ Reprod Contracept Obstet Gynecol 2018;7:4133-8. 